\title{
Open Innovation Platforms as a Knowledge Triangle Policy Tool - Evidence from Finland
}

\author{
Mika Raunio \\ Senior Researcher, mika.m.raunio@uta.fi \\ Nadja Nordling \\ Researcher, nadja.nordling@uta.fi \\ Mika Kautonen \\ Researcher, mika.kautonen@uta.fi
}

Research Center for Knowledge, Science, Technology and Innovation Studies (TaSTI), Faculty of Social Sciences, University of Tampere, 33014-University of Tampere, Finland.

\section{Petri Räsänen}

Director, Innovation and Foresight, petri.rasanen@pirkanmaa.fi

Council of Tampere Region, Kelloportinkatu 1 B, 33101 Tampere, Finland

\begin{abstract}
$\mathrm{O}$ pen innovation platforms (OIPs) as a new tool fostering the convergence of innovation, education, and research activities have been gaining popularity over the course of recent years. Innovative activities are evolving towards more agile and user-driven processes. OIPs are the key mechanism for orchestrating these processes, providing a qualitatively new space for the interactions between science, education, and innovation. Platform actors have the opportunity to share knowledge and use the urban environment as a 'living lab'.

Using the case of Tampere (Finland), the paper explores OIPs' role in the orchestration of joint innovation projects

within the framework of the 'smart city' model. The functions of the platforms in coordinating innovation are illustrated by the practices of three universities implementing the 'knowledge triangle' strategy. The initial data for the analysis of the cases were collected within the framework of the Six Cities Strategy project. The authors were guided by a participatory action research (PAR) approach and directly participated in events aimed at the development of strategy.

The results of the case analysis should contribute to the evolution of the OIPs concept both from the academic and policy perspectives. The authors highlight some tentative policy implications and recommendations.
\end{abstract}

Keywords: open innovation platforms (OIPs); knowledge triangle; network effect; university-industry cooperation; innovation policy; orchestration of innovation; Finland.
Citation: Raunio M., Nordling N., Kautonen M., Räsänen P. (2018) Open Innovation Platforms as a Knowledge Triangle Policy Tool - Evidence from Finland. Foresight and STI Governance, vol. 12, no 2, pp. 62-76. DOI: 10.17323/2500-2597.2018.2.62.76 
I $\mathrm{n}$ recent years, innovation policy has been aimed at the integration of research, education, and innovation in the framework of knowledge triangle. Previously it focused upon science parks and cluster- and sectoral-based policies, with science-based and semi-closed development projects led by a few large companies. Currently, innovation policy is evolving towards more agile and userdriven processes of innovation, in which ecosystems and open innovation and platform models are key elements. OIPs provide a new generation of co-creation spaces, fostered by advanced digitalized platform management tools. This paper focuses on the orchestration of innovation activities by higher education institutions (HEIs) with external service providers applying the platform approach.

The OIP approach enables one to engage a much broader knowledge base in order to provide user-oriented open innovation services. This approach moves beyond the living lab or experimental environment concepts and stresses service and management aspects within the framework of a digitalized platform economy context [Brynjolfsson, McAfee, 2017]. It integrates knowledge bases —including users - for mutual value creation and capture on the platforms, thus enabling network effects. Innovation services frequently reflects well-organized co-creation and open innovation practices, but we focus more on the organization of these services: how the orchestration of co-creation and open innovation is organized between the HEIs and service providers. Traditional innovation-fostering services between universities and businesses have focused on networking and matchmaking at the early phase of the innovation process. However, recent innovation services proceed in line with the ecosystem approach [Moore, 1993] and aim to provide more concrete outputs from the process and, thus, focus on later phases of the innovative process, when products are closer to the market. Innovation services with recognizable outputs and monetized value are often closer to private business services than public or semi-public support actions for innovation [Katzy et al., 2013].

The knowledge triangle and OIPs are often integrated or overlap one another, thus an analysis of OIPs would contribute to the discussion on how to foster of the development of the KT, both from a research and policy-making perspective. Using the case of Tampere (Finland), this paper describes how collaboration is organized within the framework characterized by the open innovation platform approach in the context of the knowledge triangle. First, we define the concept of an OIP, then, empirical data and methods are described, and the case studies are introduced. Finally, a discussion and short conclusion with tentative policy recommendations and some future research challenges are provided.

\section{The KT and OIP Approaches to Organizing Innovative Activity}

The KT approach emphasizes the linkages between education, research, and innovation. The KT places HEIs at the core of innovation ecosystems, and their performance is crucial for scaling up national and even European innovative performance. However, there is still a lack of illustrative examples of the KT in practice and at the university level [Markkula, 2013, p. 11]. To distinguish the KT - that is, a policy concept rather than academic approach - from the more established university, industry, and government models, such as the triple helix [Etzkowitz, 1993], we chose to focus on the orchestration of the two phenomena upon which the KT approach focuses.

Firstly, the open innovation and open co-creation activities represent the logic that is increasingly applied to the change in interactions between university, industry, and society. This suggests that the collaboration culture of the HEIs forgo silo structures or, at the very least, make them more porous. New types of environments for interaction fostering an open innovation culture, communality, and a collaborative way of working are labelled innovation platforms in this context [Markkula, 2013, pp. 17, 22; Kautonen et al., 2017; Raunio et al., 2013]. Innovation platforms facilitate open innovation and cooperation between people, education, research, and industry which increases the chances of receiving partial government support at the pre-commercial stage [Lehenkari et al., 2015]. Nevertheless, this does not really distinguish this concept from many other similar ones such as living labs [Leminen, 2015]. In this paper, we hope to accomplish this task by defining the three categories of OIPs based on their roles as orchestrators of the provision of innovative services: bilateral, multilateral, and the 'platform economy' [Brynjolfsson, McAfee, 2017; Gawer, 2009].

Due to its broad nature the KT framework does not define the innovation platform in detail, or much at all. In order to facilitate a meaningful discussion, we provide theory- and practice-based working definitions of OIPs. In the KT context, OIPs may be seen as a collaboration model that HEIs may deploy while interacting with the surrounding social environment and economy to fulfil their 'third mission'.

The discussion of innovation platforms has been vague and fragmentary in the literature and even more so in the policy and the business sectors. Thus, the study at hand is linked not only to one but 
to several academic discussions and literature streams, including regional studies, innovation policy, business management, and economics. Open innovation, as such, has been discussed extensively over the last two decades [Chesbrough, 2003; von Hippel, 2005], and fairly solid and commonly shared ideas and concepts exist within both academic and practical discussions. Among the noteworthy concepts is the 'lean-start-up' approach and its emphasis upon shorter and more agile innovation processes [Ries, 2011]. Meanwhile, the concept of a platform is much more ambiguous.

In the literature on knowledge-based regional economic development, the concept of an innovation platform refers to a policy fostering related variety [Asheim et al., 2011]. The theory on related variety suggests that combining different knowledge bases (i.e., synthetic, symbolic, and analytical) foster innovative activities between different sectors and technology bases. This focus on 'horizontal knowledge flows' and facilitating the integration of different knowledge bases distinguishes the platform approach from the cluster approach [Cooke, de Laurentis, 2010a]. This rather ambiguous and abstract definition draws, however, only a fine line between the innovation platform and the cluster approaches. We would argue that a role of openness in the OIP approach also distinguishes it from the cluster approach [Kautonen et al., 2017; Raunio et al., 2013]. Importantly, the cluster and OIP approaches introduced here are not mutually exclusive; instead, they may be overlapping and complementary, and the actors in clusters, for example, may extend their activities by setting up OIPs. The breaking up of clusters and the globalization of value-chains and 'unbundling' have made business ecosystems global. The development and innovation processes in this context offer 'bundles' that advanced and knowledge-intensive regions are eager to focus on due to their high-value creation potential for local economies.

The existing literature proposes some interpretations, which distinguish the concept of platforms from other modes of organization. In most cases, a platform is used to define how to organize productionand innovation-related interactions with external partners [Gawer, 2009; Thomas et al., 2014]. Platform defines the modes of cooperation that usually open the process for new actors and consider new forms of value creation. These include technological product platforms (e.g., iPhone), value chain platforms (e.g., the car industry), and industrial platforms (e.g., technologies). More recently, a platform has been used to describe internet-based business models deployed on digital platforms (e.g., Facebook and Uber) on which value creation is highly dependent upon the ability to attract users or developers to use the platform (network effects) [Choudary, 2013; Hagiu, 2014]. The ability to attract users or developers who create value for the platform is a shared concern in all platform approaches to various degrees.

Thus, discussions related to regional economic development remain on a fairly abstract level of related variety of knowledge bases [Asheim et al., 2011]. Despite this, it is clear that innovation platforms integrate different knowledge bases, actors, and technologies. The literature, again, offers interpretations on how to organize this communication via digital and physical environments in more detail and how to make it a profitable activity [Brynjolfsson, McAfee, 2017]. A platform is then an organizational model for the coordination of open innovation processes. Importantly, platform owners do not produce all, or any of, the key products, innovations, or services on the platform but rather facilitate the process. Instead, users of the platform provide the most value for other users of the platform or develop complementary services. The latter may be developers providing new applications for iPhone users, while the former may be Uber drivers offering a taxi services to Uber clients, who may be drivers themselves. The fact that users are creating value for each other makes it possible to foster network effects; that is, every new user on the platform provides more value for the other users [Gawer, Cusumano, 2002, 2008; Sawhney, 1998].

This provides many opportunities for knowledge-based developments and policy measures that frequently refer to intermediaries that aim to bring together knowledge producers and users in order to foster innovation. There are several private services working as digitalized platforms providing open innovation services (e.g., Innocentive or NineSigma) that may be considered innovation intermediaries [Howells, 2006] and whose practices link clients with innovation challenges and knowledge holders with potential solutions. They are frequently considered more suitable for organizing partnerships than traditional semi-public development agencies. The qualities of these platforms include welldefined innovation processes that may be monetized, for which ROI is visible for the service users [Katzy et al., 2013; Hallerstede, 2013].

It should be noted that innovation intermediaries [Howells, 2006] work according to a bilateral or multilateral platform model, by providing, for example, science park environments and cluster programs with actors (e.g., research institutions) that bring in other actors (e.g., companies) to the platform. This resembles a shopping mall business model, where good quality shops attract customers that encourage more shops to set up their branches at the mall, fostering a network effect 
based on mutual benefits and complementary services (e.g., cafeterias and parking spaces), which make it even more feasible for both groups of actors (i.e., retailers and shoppers) to use the platform that the shopping mall offers for their interaction as a multilateral or bilateral platform [Boudreau, Hagiu, 2009, p. 177]. Science park environments have, in principle, benefitted from network effects and complementary services that make platforms attractive to their users (e.g., industry-university collaboration). Recently intermediary activities have applied digitalized solutions that aim to increase the efficiency of the network effect substantially.

The business model of open innovation wholly corresponds with the characteristics of a platform as defined by the literature. In the majority of cases the open format of platform collaboration encourages innovative activity, it provides mutual benefits in new value creation. The platform and platform economy concepts [Gawer, Cusumano, 2002; Choudary, 2013], may be seen as a continuation of the discussion on networks and network society in the 1990s [Castells, 1996] as an attempt to understand the new logic behind interactions between economic players. Currently, the term 'platform' is used to explain and describe the emerging modes of interaction in both the social and economic fields. In general, the platform approach reflects the demands of the new socio-technological paradigm, in which megatrends in the digitalization of technology (e.g., internet-based business), and globalization of the markets (e.g., business ecosystems) also transform behavior in the economy (e.g., a sharing economy) and foster the emergence of new modes for organizing cooperation in innovative (and production) activities.

In sum, the ability to combine different knowledge bases (i.e., synthetic, symbolic, and analytical) and forms of knowledge in general (i.e., science- and experience-based knowledge, codified knowledge, and tacit knowledge) as well as social capital (or trust) are frequently seen as the key to fostering innovation by policy and management. Both digital and physical platforms may enhance this knowledge 'crosspollination', for example, by integrating different industries and research disciplines, or user groups for co-creation processes (e.g., this may be done in living labs in order to utilize experience-based knowledge). Various innovation centers, platforms, labs, or science parks are largely discussed in the literature, and they are broadly used as examples of how to implement innovation policy [Boschma, 2005; Cooke, de Laurentis, 2010a, 2010b; Harmaakorpi et al., 2011]. Also, the ability to accelerate the innovation process from knowledge to markets in an agile and user-oriented innovation process is critical. Organizing and engaging users and other external actors so that they are part of the innovation process (e.g., in living labs or proto projects) are typical steps towards implementing this goal. Chesbrough [Chesbrough, 2003], Ries [Ries, 2011] and Thiel [Thiel, 2014] are among the key authors discussing these dynamics.

The discussion also relates to business and innovation ecosystems and how they facilitate open innovation activities. Examples include user-communities, living labs, and other methods to integrate users or other external parties in innovation processes during the pre-market stage. It is appropriate to distinguish business ecosystems from innovation ecosystems, according to their expected outputs. In business ecosystems, the aim is to organize value creation and value appropriation in an systemic setting, while 'the main output of innovation ecosystems is the increase of information flows and collaboration and therefore the creation of new business-relevant knowledge, ideas, and technologies that lead to new products, successful companies, and economic growth' [Huhtamäki, Rubens, 2016, p. 11]. The internet-powered and digitalized multilateral platform model seeks network effects in the provision of innovative services, the scaling of production, and lowering of marginal costs. These things encourage the emergence of services that foster the knowledge triangle in accordance with the latest developments of the 'platform economy' [Brynjolfsson, McAfee, 2017; Sundararajan, 2016]. Thus, our aim is to describe how to orchestrate the innovative activities of these business and innovation ecosystems, to identify the relationships between service providers, the possible benefits from fostering cross-pollination, and open innovation within the framework of these platforms.

\section{National and Regional Context of KT-related Strategies}

\section{System of HEIs and Innovation Policy}

According to some studies, university and industry collaboration is more intensive in Finland than in most of the European Union (EU). However, while the share of the companies cooperating with HEIs was $33 \%$, only $4.9 \%$ of firms announced that the interactions with the university mattered. Still, both figures are significantly higher than the average among EU countries [Finnish Government, 2009; Pelkonen, Nieminen, 2015]. In short, HEIs' impact upon firms' real innovative outcomes can be considered as rather moderate and typically more indirect and therefore perhaps difficult to recognize, than direct and linear. 
Table 1. Key programs for the innovative development of regions in Finland

\begin{tabular}{|l|l|l|}
\hline \multicolumn{1}{|c|}{ Name } & Years & \multicolumn{1}{c|}{ Source } \\
\hline Centres of Expertise I, II, III & $1994-2013$ & {$[$ Kavonius, 2013] } \\
\hline Open Innovation Environments & $2008-2012$ & {$[$ Turunen, 2010] } \\
\hline Innovative Cities, INKA & $2014-2020$ & {$[$ Tekes, 2013] } \\
\hline Six Cities Strategy of Finland: Open and Smart Services & $2015-2020$ & [Six Cities Strategy Office, 2016] \\
\hline Source: compiled by the authors. & \\
\hline
\end{tabular}

The share of research and development (R\&D) expenditures in total GDP has been among the highest in the world in Finland from the early 2000s and onwards. The share of R\&D expenditures in Finland's GDP peaked in 2009 at $3.9 \%$, but then it decreased to $3.1 \%$ in 2015. The major reason for this decline is lower product development investments in the private sector, whereas the higher education sector and the public sector reduced their investments only slightly from the peak years [Statistics Finland, 2016]. The incentives to cooperate with industry or to conduct innovation-related activities are to a great extent lacking in the basic funding mechanisms of Finnish HEIs, but they are included in the practices of the HEI's main government funding organization. Tekes, the National Agency for Technology and Innovation ${ }^{1}$, demands and fosters cooperation between the private sector and the universities in its funding programs. Furthermore, the European Social Fund (ESF) and the European Regional Development Fund (ERDF) projects encourage multilateral cooperation by focusing on supporting universities of applied sciences (UASs) (i.e., polytechnics) [Hyytinen et al., 2012]. The direct funding from companies is fairly modest in the case of both types of HEIs and concentrated at the few universities of technology or medical schools among the universities. The direct funding from companies has also decreased over recent years [Vipunen.Fi, n.d.].

At research universities the share of external funding (1.215 million euros in 2015) was around 55\% of the total research funding (i.e., the highest figure was 59\% from the Academy of Finland and Tekes). At the UASs, R\&D funding was 167 million euros in 2013 in total (major funding came from the ministries and the EU's development funds). Domestic companies provided less than $10 \%$ for external funding and foreign companies provided only a small fraction of the funding for research universities and virtually nothing for UASs [Vipunen.Fi, n.d.].

In sum, the profiles of universities and UASs differ from each other very clearly in terms of the amount and sources of external R\&D funding. Further, cooperation with businesses is limited to a few universities in terms of corporate funding (e.g., in 2014, the University of Tampere alone gathered 57\% of the total national funding from foreign companies in Finland, mainly due to its vaccination-related research; Aalto University (technology-oriented) and Tampere University of Technology together collected about $45 \%$ of the total national funding from domestic companies).

Place-based innovation policies provide support for the development of knowledge triangle activities. In the 1960s, Finland established a wide network of general universities and universities of applied sciences, which subsequently became the base for carrying out regional programs for innovative development, including the interactions between educational institutions and local and regional enterprises and wider society (Table 1).

The most recent national programs link innovation strategies closely to economic development at the regional and urban levels. For example, INKA (Tekes funded) is embedded in the regional and urban development framework and aims to foster the innovative activities of firms and develop 'internationally attractive innovation clusters in Finland' [Tekes, 2013]. It partially overlaps with the Six Cities Strategy program (ERDF-funded) which focuses on building the competences of cities and local public actors to foster (open) innovation. Since the latter provides the context for this study, we define it in more detail later on.

\section{The Innovation Landscape of Tampere Region}

The Tampere region is centrally located in southwestern Finland and, together with the capital city region of Helsinki, forms the most dynamic regional economic zone in the country in terms of population growth and investments. The administrative Tampere region has approximately 500,000 inhabitants, of which about half live in the city of Tampere.

\footnotetext{
Named Business Finland from the beginning of 2018.
} 


\section{Table 2. Profiles of the HEIs in Tampere}

\begin{tabular}{|c|c|c|c|}
\hline HEIs in Tampere & $\begin{array}{c}\text { University of Tampere } \\
\text { (UTA) }\end{array}$ & $\begin{array}{l}\text { Tampere University of } \\
\text { Technology (TUT) }\end{array}$ & $\begin{array}{c}\text { Tampere University } \\
\text { of Applied Sciences } \\
\text { (TAMK) }\end{array}$ \\
\hline Year of establishment & 1960 & 1965 & 1996 \\
\hline Profile & Society and Health & Industrial & Polytechnic \\
\hline $\begin{array}{l}\text { Main areas of research and } \\
\text { education }\end{array}$ & $\begin{array}{l}\text { - Information, information } \\
\text { technology and knowledge } \\
\text { - Cities, the environment } \\
\text { and the regions } \\
\text { - Journalism and media } \\
\text { - Changes of society } \\
\text { - Individual and collective } \\
\text { health } \\
\end{array}$ & $\begin{array}{l}\text { - Signal processing } \\
\text { - Optics and photonics } \\
\text { - Intelligent machines } \\
\text { - Bio-modelling } \\
\text { - Built environment }\end{array}$ & $\begin{array}{l}\text { - Computer science } \\
\text { - Media and graphics } \\
\text { - Digital gaming } \\
\text {... and many others }\end{array}$ \\
\hline Students, 2014 & 14952 & 8390 & 10290 \\
\hline $\begin{array}{l}\text { Teaching and research } \\
\text { personnel, } 2014\end{array}$ & 1068 & 1118 & 421.4 \\
\hline Foreign students, 2013 & 535 & 797 & 293 \\
\hline Degrees/graduates, 2014 & 2571 & 1598 & 1856 \\
\hline HEI spin-offs, 2014 & .. & 3 & 2 \\
\hline $\begin{array}{l}\text { Basic budget funding, mln. } \\
\text { euros, } 2014\end{array}$ & 116.3 & 82.0 & 65.3 \\
\hline
\end{tabular}

The main HEIs in the region are University of Tampere (UTA), Tampere University of Technology (TUT), and Tampere University of Applied Sciences (TAMK) (see Table 2) ${ }^{2}$. In addition, the large R\&D facilities of the Technical Research Centre of Finland VTT (with more than 300 experts) provide companies with an R\&D partner, especially in those three areas of competence that are at the core of strong local clusters.

The integration of research, innovation, and education may be found in the strategies of all three institutions in Tampere. However, the 'third mission' and especially the links to industry and business are much more explicitly formulated in the strategies of TUT and TAMK than at UTA, which is more focused on social sciences and medicine.

According to statistics covering the last decade, every fifth inhabitant of Tampere is a student at a higher education institution and every third inhabitant, over 15 years of age, has a degree from a higher education institution. Out of almost 10,000 R\&D workers in 2010, more than half were employed by the private sector. Recently the situation changed dramatically due to lay-offs from big high-tech companies. Changes have been significant and it is likely that they are not yet fully reflected in the numbers provided in Table 1, although it seems that the employment of knowledge workers has not fallen due to the growth of many new companies and growing entrepreneurship.

It seems that the recession in the 1990s sped up development towards a more knowledge-intensive mode of the economy. In the Tampere city region, R\&D expenditures represented approximately $15 \%$ of the national total for many years (i.e., more than 900 million euros annually). This is more than 2,000 euros per inhabitant from 2006 until recently; thus, Tampere has been a national leader in R\&D intensity. Of the gross regional product, R\&D has accounted for about $7 \%$.

There are three key clusters and industrial agglomerations based on competences developed over time, and it is not likely that fundamentally new knowledge bases will emerge in the region.

The information and communication technology (ICT) cluster employed more than 6,000 engineers until 2015, but recent turbulence in the ICT industry has made the situation less clear. A key long-term strength of the cluster is its wide-ranging spectrum of industries, application domains, and product competences. Key areas include telecommunication networks, the Internet, and cloud services.

Intelligent machines represent a traditionally strong technology cluster in Tampere and its immediate vicinity, with more than 1,000 companies that account for the total turnover of more than 7 billion euros (2011) and employ more than 34,000 people. The R\&D investments account for more than 750 million euros annually, which can be attributed to the serious attempts of leading companies to maintain their innovativeness. In fact, ten world market leaders operate in Tampere. Many have

\footnotetext{
2 The three HEIs have started a merger process that will be completed at the beginning of 2019 .
} 
Table 3. Outcomes of Cluster-based Innovation Policy in Tampere

\begin{tabular}{|l|l|}
\hline \multicolumn{1}{|c|}{ Policy approach } & \multicolumn{1}{c|}{ Outcomes } \\
\hline Supply-driven & $\begin{array}{l}\text { - Rapid growth in the ICT cluster } \\
\text { - Implementation of large innovation programmes (e.g., eTampere, BioNext and Creative } \\
\text { Tampere) }\end{array}$ \\
\hline Demand-driven & $\begin{array}{l}\text { - Increasing efficiency in the large public sector (i.e., innovative procurement) } \\
\text { - Exploiting hidden potential in highly educated population (i.e., democratisation of } \\
\text { innovation) } \\
\text { - More active IPR management of companies and HEIs (e.g., Open Tampere) }\end{array}$ \\
\hline Source: compiled by the authors. \\
\hline
\end{tabular}

invested in the local innovation environment (e.g., the world's largest production automation and testing site for container terminals, as the Cargotec Group invested approximately 35 million euros in its new technology center in 2012).

Within the life sciences cluster, the city has a combination of multidisciplinary, technological, biomedical, and medical expertise in the education, research, healthcare, and business sectors. In recent years, the health, wellness, and biotechnology sectors in the city have been the fastest growing in Finland and received the largest number of private investments in business development.

In addition, (digital) media have been a strategic field for Tampere, mainly due to the potential that the location of the national broadcasting company has provided for the region. Of course, it has in many ways been integrated into the strong ICT cluster. ICT and digitalization clearly influence all the clusters of the region.

The knowledge-based development policy in the Tampere over the past decades includes the construction of basic innovation infrastructure, such as universities and their mechanisms for technology transfer, science parks, programs for centers of expertise and clustering, and so forth. Large, locally initiated public and private partnership-based innovation programs have generated cumulative competences and confidence to conduct further innovation policy operations with expected high impacts (see, e.g., [Wallin, Laxell, 2013]). The latter part of the 1990s saw the emergence of a supplydriven, cluster-based innovation policy, followed by a more demand-driven approach since 2005. Outcomes of both supply- and demand-driven approaches are represented in Table 3.

OIPs as tools with the potential to implement strategic goals under the open innovation and 'smart city' frameworks are applied, for example, in the territorial strategies and regional funding decisions of the Regional Council.

\section{Context, Data, and Method of the Study}

Our study aims to reflect the OIP approach with smart city development as a part of the aforementioned Six Cities Strategy implemented by the six largest cities in Finland: Helsinki, Espoo, Vantaa, Tampere, Turku, and Oulu, with support from the ERDF. It is a strategy for sustainable urban development and it aims to increase the amount of service innovations and to promote competitive business and employment. The strategy aims to strengthen Finland's competitiveness by using the country's six largest cities as innovation development and experimentation environments in the spirit of open innovation. The strategy is based upon open 'operating models that let the entire city community participate in development work. The functional city community is seen as an entity, consisting of citizens, companies, research and development operators, and the authorities. The open operating model is based upon the creation and testing of innovations while also increasing productivity, including the development of innovative procurement practices [Six Cities Strategy Office, 2016].

OIPs are seen as environments that enable the development of new products, services, business, and markets throughout their lifespan, from idea to testing and from testing to ready-made products. OIPs engage the whole city community in the development processes. The approach is user-driven and encourages short and agile experiments in innovation activities. It may also support cities in their efforts to develop their innovative procurement practices in stakeholder engagement to provide better services and enable business development around the new services [Six Cities Strategy Office, 2016].

We utilize the participatory action research (PAR) approach to answer this question, because it aims to provide knowledge and solutions to practical problems that hinder the achievement of given goals or everyday practices. Researchers are part of the process and aim to foster reflectivity, learning, and 
Table 4. Summary Data Gathered from January 2015 to December 2017

\begin{tabular}{|l|l|l|}
\hline \multicolumn{1}{|c|}{ Sources } & \multicolumn{1}{|c|}{ Quantity } & \multicolumn{1}{c|}{ People engaged } \\
\hline Interview with OIP representatives (three cases) & 14 interviews & 14 \\
\hline $\begin{array}{l}\text { Workshops and seminars engaging people from the } \\
\text { three OIPs in question and involving them in a wider } \\
\text { discussion on OIPs (operational and strategic aspects, } \\
\text { both regionally and nationally) }\end{array}$ & $\begin{array}{l}12 \text { workshops } \\
\text { and seminars }\end{array}$ & c/a 400 (20-40 people in each) \\
\hline $\begin{array}{l}\text { Strategic and operational level engagement meetings } \\
\text { discussing OIP development (regional and national } \\
\text { level), varying events from those involving a few people } \\
\text { to festival events }\end{array}$ & c/a 100 meetings & $\begin{array}{l}\text { c/a } 500 \text { (altogether these events have } \\
\text { gathered approximately 2,000 people) }\end{array}$ \\
\hline $\begin{array}{l}\text { Discussion forum on OIP development (development of } \\
\text { views) from spring 2016 to spring 2017 }\end{array}$ & $\begin{array}{l}13 \text { platforms } \\
\text { in Tampere, } \\
25 \text { platforms } \\
\text { nationally }\end{array}$ & $\begin{array}{l}40 \text { from Tampere region, altogether } \\
80 \text { people }\end{array}$ \\
\hline Innovation project (facilitated by an OIP in question) & 2 & $\begin{array}{l}\text { The authors have been involved in } \\
\text { two innovation projects (Lintukoto } \\
\text { by Mediapolis and Demola case } \\
\text { project) }\end{array}$ \\
\hline Source: authors. & \multicolumn{2}{|l}{} \\
\hline
\end{tabular}

communication in the target community and among the stakeholders to solve the problems and to foster development [Susman et al., 1983; Ladkin, 2004]. PAR can also be a way of involving more people and new groups in the research in order to reach the set objectives [DeLyser, Sui, 2013].

The professional background and personal involvement in a series of projects listed below enabled the authors of this paper to gather the initial data:

- Developing management and analysis tools for the OIPs in the Six City Strategy project (Mika Raunio \& Nadja Nordling),

- Long experience in regional development and research in the Tampere region (Mika Kautonen),

- Membership on the regional council as an innovation and future manager, and involvement in incubating some of the regional OIPs (Petri Räsänen). ${ }^{3}$

The data has been collected as part of frequent practical joint activities with the OIP representatives, including workshops, seminars, and a facilitated discussion forum. Policy makers, developers, and other stakeholders have been engaged in various activities. These have either been recorded (and transcribed) or notes have been taken. In addition, documentary data analysis, consisting of reports, evaluations, strategy documents, project plans, and research diaries have been consulted. The data has been analyzed using an inductive data analysis method (Table 4).

The specific context for the study is the three-year spearhead projects: (1) the OIPs, in which OIPs are used to create and test new services and products in real-world conditions; (2) the open data; and (3) the open participation and services. These projects provide the models for cooperation in order to enable the city to work as a community. Additional pilot projects further support, test, and develop the spearhead projects.

Our three cases were explored in order to better understand what the OIP approach means in practice, here in the context of the KT and HEIs. Three specific examples of OIP development in Tampere focus on the practices and explain how HEIs and other key actors have worked to realize these ambitions and how they orchestrate the relevant platforms differently.

\section{Cases: the Knowledge Triangle and Orchestrating Interaction through OIPs}

Both the city of Tampere and the Tampere region (Regional Council) have fostered the innovation platform-based policy since 2008. The first application of the innovation platform approach was the New Factory and its four 'engine rooms' in 2008. The following substantial investments were Mediapolis (est. 2013) and the Campus Arena (est. 2015), which both included physical environments as a key element, while 'the original platform laboratory of New Factory' focused more upon the provision of services. For example, in the implementation plan of the wider city strategy, it is also aligned with other key policy strategies (i.e., 'to make Tampere the best place in Finland to do business'). The policy

\footnotetext{
The project team members, in addition to the authors, were as follows: senior advisor Jukka P. Saarinen (TaSTI, UTA), project manager Taina Ketola, regional analyst Anniina Heinikangas, and regional analyst Henrika Ruokonen (Council of Tampere Region).
} 
measure is defined as the 'developing and scaling of innovation platforms and environments to new lines of business in order to create new business, growth companies, and jobs' [City of Tampere, 2013].

However, the 'innovation platform', as a policy measure, is still evolving. For example, the sub-regional development agency, Business Tampere, introduces various OIPs on its website (including all three cases discussed here) where the common denominator is the opportunity for companies to somehow join innovation and development projects on these platforms. More precisely, the various forms of collaboration (e.g., living labs and demo-projects) that foster open innovation processes and wellorganized facilitation that enables the provision of numerous innovation projects, are the defining qualities of such platforms [Lehenkari et al., 2015]. However, our interest in this paper is to understand the orchestration of OIPs in the KT context. The orchestrator in this chapter refers to the actor(s) who provide value by organizing relationships and interactions on platforms for the members of the ecosystem and beyond. It should be noted that a multilateral platform model applies to both physical (tangible) and digitalized (intangible) platforms that aim to facilitate open innovation practices. By digitalizing and scaling services, it might be possible to run them more efficiently (e.g., without project funding from EU). Due to specific service processes, they may possibly create a consistent and comprehensive set of innovation services.

The cases provide examples of HEIs orchestrating both physical and digitalized platforms. Three cases accommodate the diversity of types of HEIs as well as the different partnering of key orchestrators of the platforms:

- The platform management company, New Factory International ltd. (NFI), orchestrates studentcompany innovation projects in partnerships with 58 universities in 13 countries (i.e., the Demola Network). NFI provides innovation services globally with the support of digitalized platform tools, including all three HEIs in the Tampere region.

- Finnish University Property Ltd. (SYK) works in partnership with Finnish universities (i.e., 16 locations in Finland) and, in our case of the Campus Arena, in close operation with TUT, orchestrating university and industry interactions by gathering and curating various innovation services and practices as well as companies to the new building on campus.

- The Finnish Broadcasting Company (YLE) is a 'keystone company' located on the premises owned by Technopolis Ltd. (i.e., a company that rents out the premises for businesses in four locations in Finland and more in five other countries) with the TAMK.

Three simplified models represent the close partnership of HEIs with companies that focus on providing tangible (e.g., physical premises) or intangible assets (e.g., services, software or processes) that aim to foster $\mathrm{KT}$ activities to varying extents.

\section{Demola: Digitalized Global OIP for the Local Innovation Ecosystem}

The Demola network is a 'lean corporate innovation engine' and a 'global co-creation platform to connect universities and business', according to its website 4 . The Demola network is facilitated by NFI, a platform management company that has more than 650 customers. The concept of the Demola network was established and developed in Tampere by the local development agency as a part of the New Factory Innovation Center in 2008. In 2011, the NFI was established by the key persons of Demola to run and develop the growing international network of Demola sites. In 2018, Demola in Tampere was acquired by the NFI and the whole network was placed under the private 'platform management company' To a large extent, the spread of the service may be seen as a result of employing the business model of a multilateral platform with a well-defined concept and a supportive internet interface and software. The service brings together university students and companies as an 'on-line-to-off-line type of a service that uses a digital platform to link the users, but an actual service process takes place in a physical space and provides benefits for both sides of the platform [Brynjolfsson, McAfee, 2017].

At first, Demola was part of NFI, which represented a new type of 'innovation platform laboratory', an innovation center in Tampere. It consisted of four 'engine rooms': (1) Demola (to generate prototypes and demonstrations from ideas typically coming from private firms, developed in projects by multidisciplinary student teams); (2) Protomo (a similar service for self-employed persons and experts often in the process of a career transition); (3) Suuntaamo (an open test laboratory for new products and processes); and (4) Accelerators (a service for start-ups). The aim was to be 'customer focused, down-to-earth, agile, cost-efficient and effective' and, then, clearly to foster the development of new

Available at: https://www.demola.net/, accessed 09.05.2018. 
types of practical innovative services compared to traditional cluster-based R\&D projects [Raunio et al., 2013].

Up to present, a typical collaboration scenario in Demola includes a multidisciplinary team gathering (the cross-fertilization of knowledge) students from the universities and polytechnic institutes, and a project contract signed by the stakeholders (the firm and the team), including issues related to intellectual property rights (IPRs) and the timetable. The demonstration of the concept or prototype is carried out by the student team, followed by a project evaluation and the finalization of license agreements.

The benefits of Demola are not limited to a single firm, since the student team also has the opportunity to utilize the intangible assets created by setting up a start-up company in the case that the firm does not acquire a license for the IPRs. Students may also be recognized for their talent, leading to employment. All the IPRs generated during the project belong to the student team. At the end of the project, the partner firm can acquire a license for the results and reward the students for their work, in accordance with the performance criteria agreed upon earlier. The method is effective due to the well-defined IPR framework (which avoids the contractual costs of collaboration), the focus on the concepts pre-selected by the firms, and the diverse set of skills and ideas of the students working on it. Importantly, in case of Tampere, the projects are conducted by students from the three different HEIs, with wide disciplinary backgrounds. Student are also provided by academic credit by the participating HEIs, with varying practices.

However, in terms of orchestration, the most distinct quality is that this structure makes the service scalable, and the digitalized customer interface and management process facilitates the management of the open innovation projects on a global scale. NFI employs around ten people (with less than one million euros of turnover), and there is clearly one core service process that it efficiently repeats on the platform in cooperation with HEIs.

Demola facilitates a fairly complex student project, while usually the on-line-to-off-line platforms provide simple and single service practices (e.g., Uber's taxi services). As a (transaction) platform [Evans, Gawer, 2016], it connects mainly two groups of users: university students (and researchers as well) and local firms (or other organizations). The global network also provides data to be analyzed in order to develop the organizational innovation management capabilities of the platform company. This may be seen as an investment in the intangible innovation infrastructure. However, it may be claimed that the full value creation potential of the global network has not yet been utilized, from the customer's (companies and HEIs) point of view. It seems that innovation projects are taking place mostly at the local level around each individual Demola location, rather than among the global network. Therefore, global networks and digitalization do not solve the problem of distance in innovation as such, and international innovation projects do not emerge simply due to global network of orchestrators and platform owners. The active role of HEIs themselves as well as other orchestrators are required for further developments. In sum, Demola, as a co-orchestrator of OIPs, may be labelled a 'Global innovation platform service'.

\section{Campus Arena: Physical and Digital OIPs to Revitalize the Local Innovation Ecosystem}

The Campus Arena is a building on the TUT campus, which is owned by SYK. Even though it accommodates some of the basic services for the university (e.g., a library), its profile is strongly built upon a new kind of university and industry collaboration activities. It is marketed as a 'meeting place for science, research, and technology'. Compared to Demola or Mediapolis, the Campus Arena more clearly serves the KT activities of one institution (TUT), as it is located in a central place on the campus and is a new landmark of the TUT (which opened in September 2015). Consequently, over the course of the study at hand, many of its KT-related practices were still evolving.

The premises are owned by the SYK, a fairly new actor in the real-estate business and was established in 2009 to maintain virtually all the premises hosting Finnish HEIs (excluding Aalto University and the University of Helsinki), and it has been actively searching for new and innovative solutions (e.g., a learning campus and co-creation) to increase the value of the premises.

The Campus Arena was developed by the SYK and the TUT by engaging companies, students and university personnel to search for feasible collaboration models as well as spatial solutions. Partly this was due to a need to renew the business cooperation models, as its long-term partner Nokia had closed its major research and development facilities next to the campus of TUT. In the selection of tenant companies, the TUT holds the right to veto in order to ensure that they fit into the research and educational goals of the university. The largest single client of the Campus Arena is also TUT. 
The physical office spaces were planned to support collaboration (e.g., co-working spaces, big rooms, etc.) and services were planned to foster opportunities for actors to move 'across the borders in their value creation process'. This may be seen as an attempt to move from networking and interaction towards more 'organized collisions' to support the innovation activities or co-creation between the actors. Specifically, for the Campus Arena, with an emphasis on co-creation and co-working, opportunities were developed in the Campus Club by the SYK, whereby the premises are not rented to the companies, but they may buy a membership in the club for three years. The club offers flexible spaces for long-term, face-to-face collaboration. Compared to many 'cluster-based' projects in which teams may work apart from each other, and the most interactive link between the companies is the project steering group, this model emphasizes more direct interaction among the key individuals and the self-organization of members.

Campus Arena hosts companies offering innovation-supporting services; the building itself includes sensors that enable its use for various analyses, and TUT may organize workshops (e.g., those with students and companies) or use laboratories on the campus. It is worth noting that specialized entities provide various services and support activities for companies in order to organize innovation activities with the university or with other companies. For example, DIMECC (Digital, Internet, Materials \& Engineering Co-Creation) which is owned by several HEIs, knowledge intensive companies, and other stakeholders labels itself as a 'leading breakthrough-oriented co-creation ecosystem that speeds up time to market' whose innovation platform offers both digital and process services. These include digitalized innovation services like the 'Demobuuster' service that is for sale for the companies who seeks 'to speed up the commercialization of their software demos'. Such a process is not very different from the Demola process as such, but it should be noted that practical implementation rather than conceptual definition explains the success or failures of these services. Another example is SMACC (Smart Machines and Manufacturing Competence Centre), owned by the University of Technology and Technical Research Centre of Finland (VTT), offering a one-desk service to manufacturing companies for research and innovation services. In sum, DIMECC and SMACC are entities owned by the business and research communities that aim to foster innovativeness in their respective fields, to benefit the community and ecosystem at large.

Thus, the Campus Arena offers a physical platform for various independent service providers and their real-life innovation services to foster the interactions between the university and industry. Tenants (i.e. businesses) of the arena are aligned with the objectives of research and education at TUT. The model resembles an 'innovation service shopping mall', where complementary services make it more attractive for the users (e.g., companies, university researchers, students) to deploy operations there. As an OIP orchestration model, Campus Arena is aligned with the strong research orientation and strategy of TUT with many specialized innovation supporting services and may be labelled an 'innovation ecosystem hub'.

\section{Mediapolis: A Physical OIP for the Local Business Ecosystem}

Mediapolis gathers together over 700 employees and 600 students in Tampere at a renovated campus, which was built around the old studio complex of the national television Channel 2 and national broadcasting company (YLE) outside the established university campuses. Mediapolis aims to develop an internationally recognized center of excellence and business in the field of media, especially by fostering collaboration between the ICT and creative industries. The motivation for local stakeholders is their involvement in strengthening the media business in the Tampere region, as it has become increasingly concentrated in the capital city region of Helsinki. In fact, one of the key triggers was the organizational restructuring of YLE and plans to move activities from the Tampere studio complex to the capital city. YLE is the largest content provider in Finland.

The idea of Mediapolis was born in 2011, when YLE was seeking more cooperation with its partners to support the vitality of the creative business in the region. In 2012, the YLE sold the studio complex to Technopolis, of which the core business is the management of the business premises in several locations in six countries. The YLE and the University of Applied Sciences of Tampere (TAMK) made 20-year contracts with Technopolis and the firms moved into the premises in 2013, students of arts and media (TAMK) and media assistant students from the vocational training school (Tredu) became involved in 2014. In 2016, there were more than 30 media, ICT, and expert service companies on the campus. For the students, the campus offers the opportunity to benefit from the audio-visual equipment and studios of both companies and educational institutions, as well as cooperation opportunities with the

4 Available at: https://www.dimecc.com/, accessed 09.05.2018. 
companies (e.g., studio premises, design services, and wardrobes), and the assignments offer students opportunities to network with businesses.

Vocational training, civic engagement, and links to urban development suggest that experiencebased learning and innovation play an important role. Mediapolis, with its studio facilities, offers a technological development platform for various innovative projects. For example, companies and educational institutions have co-produced a trans-media storytelling project that cross-fertilizes different media and research fields (including universities, vocational training schools, Microsoft, Apex Games, etc.) with a contract; according to which, each actor maintains their IPR on everything they provided for the project. Clearly various knowledge bases, from symbolic to analytical, were integrated (e.g., virtual reality, acting, theatre, gaming, etc.). Mediapolis is also linked to urban development in the close by neighborhood of Tesoma, solving social problems that have accumulated there.

The ultimate goal for Mediapolis was to not only to increase the flow of innovations from the campus to industry, but also to provide benefits for other platform users. Due to the nature of the business, where the keystone company was buying and orchestrating major productions, the external innovation platform services could focus on new technological solutions, for example, those involving augmented reality, artificial intelligence, or virtual reality. The key actors of Mediapolis agreed that there is a need for a co-creation platform (i.e., one that facilitates cooperation among the small companies and another for the big players), but it should be noted that in the media business, many small companies engage in co-productions, frequently led by a major company in the field. Thus, in other words, a model where 'strategically minded keystone companies shape and coordinate the ecosystem, largely by the dissemination of platforms that form a foundation for ecosystem innovation and operations' [Iansiti, Levien, 2004], may be recognized here. YLE is a key buyer and organizer of productions involving several companies, but it has not been eager to set up a platform to further enhance the innovativeness of the ecosystem. Instead, public sector actors have been funding the emergence of these platform type of activities at Mediapolis. For example, a private media-focused accelerator service was bought to offer services and a venture capital fund for the creative industries was established (i.e., an IPR VC fund for creative industries). At Mediapolis, the service development is based upon regional development funds and projects rather than more established innovation services, although the IPR VC fund has a private base.

Mediapolis may be seen as platform with multiple technological environments, YLE as a 'keystone' company (along with couple of other larger companies), smaller companies, and start-ups as members of the ecosystem, as well as a practically oriented HEI that brings these actors within the vicinity of one another and thus to some extent fosters their interactions and innovation activities. Due to the given business- and practice-oriented set up and the lack of a strong commitment from research institutions, Mediapolis may be considered a 'business ecosystem hub', in terms its role as an OIP.

\section{Discussion and Conclusions: Towards Inclusive Innovation Policy Design}

The production of new knowledge within the platform framework occurs on the basis of the integration of its various actors [Asheim et al., 2011] and the interactions between them [Boschma, 2005]. The question is how to organize these processes efficiently among the 'ecosystems' that the platforms serve. Digitalized (intangible) and physical (tangible) innovation platforms foster interactions among the actors of the ecosystem. There are, however, differences in how sufficient proximities (e.g., physical, cognitive, social, or institutional) are sought and how innovation processes are organized among the actors on the platforms [Nooteboom et al., 2007].

The societal impact of OIPs is related to spill-overs and the serendipity that they foster. Many of the effects are intangible and relates to learning or ecosystem developments. These are very difficult to measure and visualize, and when the knowledge triangle is expanded to further solve social problems and urban development challenges, an even further revision of the measurements and indicators that are used to orchestrate the OIPs and related KT strategies are required. Thus, OIPs offer potential tools for leveraging the societal impact of KT activities. However, in the orchestration of platforms and regional innovation policies, at least three questions emerge: (1) How does the ownership of the intangible and tangible assets on the platform impact the orchestration and its focus? (2) How can one create network effects by utilizing the platform model? (3) How does one foster inclusive qualities in OIPs, especially when the approach is transferred to urban development and more active citizen engagement? In the following section we aim to answer these three questions tentatively, and to formulate further questions to be discussed in forthcoming studies and in the context of policy design processes. 
Firstly, it should be further explored how the roles of the companies partnering with HEIs - as key orchestrators and owners of the platforms - impact the development of innovation processes and services on the platforms. How does one combine the functions of physical and digitalized platforms in an appropriate way to ensure that one maximizes the benefits for the users and ecosystem development? In our examples, two of the partnering orchestrators, Technopolis and SYK, both hold physical premises valued at more than one billion euros and they have annual turnover of between 100 and 150 million euros. Their business revenues are strongly linked to these tangible assets. In the case of NFI, it mostly relies upon intangible assets (e.g., concepts, software, training, etc.) for its clients (with turnover of less than 1 million euros). The Mediapolis platform is built around one key-stone company, and the Campus Arena is mostly built around TUT and is revitalizing its KT interface with local businesses in a way that supports its research and educational goals. NFI serves the HEIs and companies with one specific innovation service concept on a global basis. The following four questions may be considered important: (1) What are the core incentives for co-orchestrators and platform owners who invest tangible or intangible assets in the KT context? (2) Why was the platform created? (3) What are the expected outcomes? (4) How do the platform owners define the returns that they seek from these activities in the first place?

As we know, intangible and tangible investments have several different qualities, including the fact that the value of an intangible asset depends on its successful performance. Further, distinctive features that provide serious competitive advantages are often much more likely to be organizational (intangible) than physical (tangible) and include elements such as management, processes, software, trust, and so on [Haskel, Westlake, 2017]. Further, in the case of sufficiently digitalized platforms, the 'perfect, instant, and free' provision of the service makes them more scalable than physical investments. However, on on-line-to-off-line platforms, the physical world creates constraints that may seriously limit the scalability of the on-line services [Brynjolfsson, McAfee, 2017]. There are crucial questions that remain in the orchestration of OIPs that combine tangible and intangible platform models to foster KT strategies: (1) Do actors seek returns from intangible or tangible investments? (2) Do they consider private returns or social returns more critical?

Secondly, key competences include the ability to create network effects. Incentives and carefully built feedback loops, rewards, and value capture processes, including IPR management practices, are crucial. For example, the lack of funding or career-related incentives at HEIs may hinder the participation of academics, or poorly executed IPR agreements may hinder the participation of companies. Therefore, the benefits and incentives that different actors provide to one another should be carefully considered, not only at the operational level but also at a more strategic level. Furthermore, a global platform management company points out that crossing the geographical distances in knowledge deployment innovation processes - does not occur simply by linking universities and companies to the same network, but further activities must be implemented to enhance the innovative interactions globally.

For platform management, the revenue logics, facilitation and curation, value creation, and capture among the members of a multilateral platform and the ability to create a network effects are crucial competences [Gawer, 2009; Hagiu, 2014]. These should be sufficiently developed in order to benefit all the users and owners of the platform in physical and digital environments.

The development of management capabilities, both on a strategic and operational level, also includes a conceptual understanding of the tangible and intangible OIP approaches, tools to measure the outcomes (including intangible spill-overs and investments in learning), recognizable service profiles, and comprehensive and compatible service offerings for the target groups in regionally relevant innovation ecosystems. The HEIs, in partnership with co-orchestrators, have to consider these capabilities and various complementary services and assets to build the appropriate entity to foster societal impacts while benefitting research and education.

Thus, this paper was able to provide only a partial answer to the questions posed earlier: Global platform management services and physical innovation hubs have different characteristics in the orchestration of HEIs' KT strategies. While there is some common ground, the role of intangible and tangible assets and returns should be well recognized when developing the OIP processes. What is the most appropriate combination of orchestrators in each case requires tailor-made solutions, as is usual in the provision of local or regional innovation policy measures.

Finally, in the context of the Six Cities Strategy, further challenges in the provision of network effects are likely to emerge, as even wider civic engagement (e.g., citizens and the unemployed) is sought after. Public procurement and open data, as a new source for innovative business, offer various opportunities to use OIPs, but the questions above should be considered. The value creation with users should not be based only upon volunteers or ostensible rewards for the 'lab rats', but upon the real benefits for 
the 'external parties'. It is furthermore important to monitor and ensure that the activities and their outcomes are societally responsible in the long run.

The OIP approach may be seen as an inclusive innovation policy for developed economies, which suggests that the inclusive processes engaging more people in innovation activities may also offer more benefits to a wider group of people. This may take place through their roles as innovators or as the users of the end-products, services, or both. Thus, the policy design is parallel to those that are suggested for many developing countries [OECD, 2014, 2015], promoting the idea that not only innovations as such are important, but also the inclusive processes and well-designed value capturing protocols.

The assumption is that people, for example, receive returns from the use of their knowledge and may create networks or learn how to engage with and benefit from the surrounding innovation ecosystem. Benefits are acquired, not only from the innovative outcomes but also from participating in the process (e.g., when solving the societal grand challenges).

Therefore, OIPs should be framed in the wider policy characterized by the inclusive innovation approach. This is not only a question of justice but also most likely a crucial part of the sustainable economic structure of societies, according to recent studies [Mazzucato, 2016; Piketty, 2014]. Therefore, developing new modes of deploying the knowledge of society — including HEIs — and the responsible qualities in both processes and outcomes should be secured in terms of equity and sustainable economic growth.

The inclusive approach is parallel to the user-driven or open innovation approaches, but it has a different point of departure. In open and user-driven approaches, as well as in creativity discussions more generally, the innovation process is believed to benefit from the wider engagement of users, various stakeholders, or professionals as providers of useful knowledge and insights into the process.

The platform approach, with users providing value to each other, the facilitation of network effects, and the combinations of digital solutions and physical innovation hubs should be considered carefully as a significant part of the solution to contemporary challenges in both KT policies and regional knowledge-based development policies. This all suggests that novel management and policy design capabilities are required to orchestrate increasingly intangible assets and complex processes.

\section{References}

Asheim B., Boschma R., Cooke P. (2011) Constructing regional advantage: Platform policies based on related variety and differentiated knowledge bases. Regional Studies, vol. 45, no 6, pp. 1-22.

Boschma R. (2005) Proximity and Innovation: A Critical Assessment. Regional Studies, vol. 39, no 1, pp. 61-74.

Boudreau K., Hagiu A. (2009) Platform Rules: Multi-Sided Platforms as Regulators. Platforms, Markets and Innovation (ed. A. Gawer), London: Edward Elgar, pp. 163-191.

Brynjolfsson E., McAfee A. (2017) Machine, Platform, Crowd: Harnessing Our Digital Future, New York: W.W. Norton and Company.

Castells M. (1996). The Rise of the Network Society: The Information Age: Economy, Society, and Culture, vol. I, Oxford: Blackwell Publishers.

Chesbrough H. (2003) Open Innovation: The New Imperative for Creating and Profiting from Technology, Boston, MA: HBS Press.

Choudary S.P. (2013) Platform power. Secrets of billion-dollar internet startups. Available at: http://platfromed.info, accessed 15.02.2016.

City of Tampere (2013) Tampere, Working Together for a Bright Future. Tampere City Strategy 2025, Tampere: City of Tampere. Available at: https://www.tampere.fi/tiedostot/k/P1IFwM6Al/Tampere_City_Strategy.pdf, accessed 16.11.2017.

Cooke P., de Laurentis C. (2010a) The matrix: Evolving policies for platform knowledge flows. Platforms of Innovation: Dynamics of New Industrial Knowledge Flows (eds. P. Cooke, C. de Laurentis, S. MacNeill, C. Collinge), London: Edward Elgar Publishing, pp. 311-360.

Cooke P., de Laurentis C. (2010b) Platforms of innovation: Some examples. Platforms of Innovation: Dynamics of New Industrial Knowledge Flows (eds. P. Cooke, C. de Laurentis, S. MacNeill, C. Collinge), London: Edward Elgar Publishing, pp. 271-310.

DeLyser D., Sui D. (2013) Crossing the qualitative-quantitative divide II: Inventive approaches to big data,mobile methods, and rhythmanalysis. Progress in Human Geography, vol. 37, pp. 293-305.

Etzkowitz H. (1993) Enterprises from Science: The Origins of Science-based Regional Economic Development. Minerva, vol. 31, no 3, pp. 326-360.

Evans P.C., Gawer A. (2016) The Rise of the Platform Enterprise. A Global Survey (The Emerging Platform Economy Series Report no 1), New York: The Center of Global Enterpise.

Finnish Government (2009) Evaluation of Finnish National Innovation System (Full report), Helsinki: Ministry of Education, Ministry of Employment and the Economy. Available at: https://www.etla.fi/wp-content/uploads/ InnoEvalFi_FULL_Report_28-Oct-2009.pdf, accessed 18.04.2017.

Gawer A. (2009) (ed.) Platforms, Markets and Innovation, New York: Edward Elgar.

Gawer A., Cusumano M. (2002) Platform Leadership: How Intel, Microsoft and Cisco Drive Industry Innovation, Boston, MA: Harvard Business School Press.

Gawer A., Cusumano M. (2008) How companies become platform leaders. MIT Sloan Management Review, vol. 49, no 2, pp. 28-35. 
Hagiu A. (2014) Strategic decisions for multisided platforms. MIT Sloan Management Review, vol. 55, no 2, pp. 71-80.

Hallerstede S.H. (2013) Managing the Lifecycle of Open Innovation Platforms, Wiesbaden: Springer Gabler. DOI 10.1007/978-3-658-02508-3.

Harmaakorpi V., Tura T., Melkas H. (2011) Regional innovation platforms. Handbook of Regional Innovation and Growth (eds. P. Cooke, B. Asheim, R. Boschma, R. Martin, D. Schwartz, F. Todtling), Cheltenham: Edward Elgar, pp. 556-572.

Haskel J., Westlake S. (2017) Capitalism without Capital. The Rise of the Intangible Economy, Princeton, NJ: Princeton University Press.

Howells J. (2006) Intermediation and the role of intermediaries in innovation. Research Policy, vol. 35, pp. 715-728.

Huhtamaki J., Rubens N. (2016) Exploring Innovation Ecosystems as Networks: Four European Cases. Proceedings of the 49th Hawaii International Conference on System Sciences (HICSS), Koloa, HI, USA, 2016, pp. 4505-4514. DOI:10.1109/HICSS.2016.560.

Hyytinen K., Kivisaari S., Lehtoranta O., Toivanen M., Loikkanen T., Lyytinen T., Oksanen J., Rilla N., van der Have R. (2012) Funder, Activator, Networker, Investor... Exploring Roles of Tekes in Fuelling Finnish Innovation (Tekes Review no 289/2012). Helsinki: Tekes.

Iansiti M., Levien R. (2004) The Keystone Advantage: What the New Dynamics of Business Ecosystems Mean for Strategy, Innovation, and Sustainability, Boston, MA: Harvard University Press.

Katzy B., Turgut E., Holzmann T., Sailer K. (2013) Innovation intermediaries: A process view on open innovation coordination. Technology Analysis \& Strategic Management, vol. 25, no 3, pp. 295-309. Available at: http://dx.doi. org/10.1080/09537325.2013.764982, accessed 17.03.2018

Kautonen M., Pugh R., Raunio M. (2016) Transformation of regional innovation policies: From "traditional" to "next generation" models of incubation. European Planning Studies, vol. 25, no 4, pp. 620637. DOI: $10.1080 / 09654313.2017 .1281228$.

Kavonius V. (2013) Innovation Policies in Finland, Helsinki: Ministry of Employment and the Economy. Available at: $\quad$ https://www.bothnianarc.net/-en/wp-content/uploads/2013/02/Innovation-Policies-in-Finland-VexiOulu-19.2.2013.pdf, accessed 13.04.2018.

Ladkin D. (2004) Action research. Qualitative Research Practice (eds. C. Searle, F.G. Gobo, J.F. Gubrium, D. Silverman), London: SAGE, pp. 536-548.

Lehenkari J., Pelkonen A., Oksanen J. (2015) Innovaatioalustat 2015 [Innovation platforms 2015] (Policy brief. MEE reports 45/2015), Helsinki: Ministry of Employment and the Economy (in Finnish).

Leminen S. (2015) LivingLabs as Open Innovation Networks: Networks, Roles and Innovation Outcomes (PhD Thesis), Aalto: Aalto University. Available at: https://aaltodoc.aalto.fi/bitstream/handle/123456789/17899/ isbn9789526063751.pdf? sequence $=1$ \&isAllowed $=y$, accessed 23.02.2017.

Markkula M. (2013) The knowledge triangle renewing the university culture. The Knowledge Triangle: Re-inventing the Future (eds. P. Lappalainen, M. Markkula), Helsinki: SEFI, Aalto University, Valencia University, pp. 11-32.

Mazzucato M. (2016) From Market Fixing to Market Creating: A New Framework for Innovation Policy. Industry and Innovation, vol. 23, no 2, pp. 140-156.

Moore J. (1993) Predators and Prey: A New Ecology of Competition. Harward Business Review (May-June issue), pp. 75-86. Available at: http://blogs.harvard.edu/jim/files/2010/04/Predators-and-Prey.pdf, accessed 17.02.2018.

Nooteboom B., van Haverbeke W.P.M., Duijsters G.M., Gilsing V.A., van der Oord A. (2007) Optimal cognitive distance and absorptive capacity. Research Policy, vol. 36, pp. 1016-1034.

OECD (2014) All on board. Making inclusive growth happen, Paris: OECD.

OECD (2015) Innovation policies for inclusive growth, Paris: OECD.

Pelkonen A., Nieminen M. (2015) Korkeakoulujen ja tutkimuslaitosten yhteistyö ja yhteistyön esteet [Collaboration and co-operation between higher education and research institutions]. Helsinki: Ministry of Education and Culture (in Finnish).

Piketty T. (2014) Capital in the Twenty-First Century, Cambridge, MA: Harvard University Press.

Raunio M., Saarinen J., Kautonen M. (2013) Models for International Innovation Policy: Transnational Channels and Regional Platforms: Fostering Globalizing Innovation Communities in Finland and Abroad (TaSTI Working Paper no 9), Tampere: University of Tampere.

Research.Fi (n.d.) Research Information Hub. Available at: https://research.fi/, accessed 19.04.2018.

Ries E. (2011) The Lean Startup. How Today's Entrepreneurs Use Continuous Innovation to Create Radically Successful Businesses, New York: Crown Business.

Sawhney M.S. (1998) Leveraged high-variety strategies: From portfolio thinking to platform thinking. Journal of the Academy of Marketing Science, vol. 26, no 1, pp. 54-61.

Six Cities Strategy Office (2016) Six Finnish cities join forces to become better and smarter. Available at: http://6aika. fi/in-english, accessed 22.01.2018.

Statistics Finland (2016) Science, Technology and Information Society. Available at: www.stat.fi, accessed 19.01.2018.

Sundararajan A. (2016) The Sharing Economy: The End of Employment and the Rise of Crowd-Based Capitalism, Cambridge, MA: MIT Press.

Susman G.I. (1983) Action Research: A Sociotechnical Systems Perspective. Beyond Method: Strategies for Social Research (ed. G. Morgan), London: Sage Publications, pp. 95-113.

Tekes (2013) INKA - Innovative Cities. New Policy Programme for Promoting World-class Innovation Hubs (20142020), Helsinki: Tekes. Available at: https://tapahtumat.tekes.fi/uploads/8bf12378/INKA-6506.pdf, accessed 13.04.2018.

Thiel P. (2014) Zero to One. Notes on Startups, or How to Build the Future, New York: Crown Business. Available at: http://gsl.mit.edu/media/programs/south-africa-summer-2015/materials/0to1.pdf, accessed 26.08.2017.

Thomas L., Autio E., Gann D.M. (2014) Architectural leverage: Putting platforms in context. Academy of Management Perspective, vol. 28, no 2, pp. 198-219.

Turunen I. (2010) Open (Information and Open) Innovation Strategies in Finland - Paving the Way for Open Science. Paper presented at the FinnOA symposium «Open access to research results», 3rd May 2010. Available at: http:// www.finnoa.fi/wp-content/uploads/2010/05/turunen.pdf, accessed 13.04.2018.

Vipunen.Fi (n.d.) Education Statistics Finland. Available at: https://vipunen.fi/en-gb/, accessed 19.01.2018.

von Hippel E.A. (2005) Democratizing Innovation, Cambridge, MA: MIT Press.

Wallin J., Laxell P. (2013) Alueet globaaleissa ekosysteemeissä. Osaamiskeskusohjelman loppuarviointi. Työ- ja elinkeinoministeriön julkaisuja, Innovaatio [Regions in Global Ecosystems - Final Evaluation of the Center for Expertise Program. Publications of the Ministry of Employment and the Economy, Innovation], Helsinki: Ministry of Employment and Economy. Available at: https://tem.fi/documents/1410877/2864661/Alueet+globaaleissa+eko systeemeiss\%C3\%A4+04062013.pdf, accessed 17.04.2018 (in Finnish). 